\title{
ANÁLISE COMPARATIVA DO RELATÓRIO DE CONTROLE AMBIENTAL DA PERFURAÇÃO DE 6 POÇOS DE PETRÓLEO NO CAMPO DE PORTO CARÃO EM CARNAUBAIS/RN COM O TERMO DE REFERÊNCIA DO IDEMA (RN)
}

\author{
Werner Kleyson da Silva Soares \\ Doutorando em Engenharia de Produção (UFPE). E-mail: Werner_soares@hotmail.com \\ Valdenildo Pedro da Silva \\ Professor do Instituto Federal de Educação, Ciência e Tecnologia do Rio Grande do Norte. \\ E-mail: valdenildo@cefetrn.br
}

\section{RESUMO}

Neste trabalho, por meio de referenciais bibliográficos e da legislação vigente, procura-se fazer uma análise comparativa entre o Relatório de Controle Ambiental da Perfuração de Seis Poços de Petróleo no Campo de Porto Carão no Município de Carnaubais/RN Revisão 00 e o Termo de Referência, disponibilizado pelo Instituto de Defesa do Meio Ambiente do Rio Grande do Norte (IDEMA). O Termo de Referência é um documento não obrigatório usado como guia na elaboração de Estudos de Impacto Ambiental/Relatório de Impacto ao Meio Ambiente (EIA/RIMA) e afins, como o Relatório de Controle Ambiental (RCA). A atividade de perfuração para conjuntos de poços é dispensada da obrigatoriedade de elaboração de um EIA/RIMA, sendo realizado em seu lugar um RCA. Esse documento pode ser considerado como um Estudo de Impacto Ambiental menos aprofundado. No RCA analisado, verificaram-se falhas na organização do conteúdo, carência de opções de estratégias de mitigação (como previsto da resolução CONAMA n ${ }^{\circ}$ 001/86), entre outras. Espera-se que este estudo tenha salientado pontos positivos, bem como possíveis limitações do RCA em análise de forma satisfatória. Pretende-se, com este estudo, contribuir para a elaboração de futuros estudos de impactos ambientais, minimizando tais limitações e valorizando os pontos positivos.

PALAVRAS-CHAVE: Licenciamento Ambiental Onshore, Petróleo, Relatório de Controle Ambiental, Termo de Referência.

\section{COMPARATIVE ANALYSIS OF THE ENVIRONMENTAL CONTROL REPORTS FOR DRILLING OF SIX OIL WELLS IN THE FIELD OF PORTO CARÃO-CARNAUBAIS WITH THE REFERENCE TERMS OF IDEMA (RN)}

\begin{abstract}
In this work, using references and the current laws, was analyzed the adequacy of the Environmental Control Report of the Perforation of 6 Wells of Oil in the Field of Porto Carão in the City of Carnaubais/RN to the Term of Reference from the IDEMA in the state of the Rio Grande do Norte. The Term of Reference is a not obligatory document used as guide in the elaboration of Studies of Environmental Impact/Report of Impact to the Environment (EIA/RIMA in Portuguese) and similar, as the Reports of Environmental Control (RCA in Portuguese). The activity of perforation for sets of wells is excused from the obligatoriness of elaboration of a EIA/RIMA, being carried through in its place a RCA. This document would be considered like a Study of Environmental Impact with less deepness. In the RCA in question was observed imperfections in the organization of the
\end{abstract}


content, lack of the options of mitigations' strategies (as in resolution CONAMA ${ }^{\circ}$ 001/86), among others. It is expected this article had considered positive points and negative points as well, in a satisfactory way. It is intended contribute for future environmental impact studies, minimizing those limitations and enhancing positive points.

KEYWORDS: Onshore Environmental Licensing, Oil, Environmental Control Report, Term of Reference. 


\section{ANÁLISE COMPARATIVA DO RELATÓRIO DE CONTROLE AMBIENTAL DE PERFURAÇÃO DE 6 POÇOS DE PETRÓLEO NO CAMPO DE PORTO CARÃO EM CARNAUBAIS/RN COM O TERMO DE REFERÊNCIA DO IDEMA (RN)}

\section{INTRODUÇÃO}

A estrutura da sociedade atual estimula uma tensão entre economia e ecologia. Enquanto a economia estimula a competição, expansão e dominação, a ecologia incentiva a cooperação, conservação e parceria (CAVALCANTI et. al., 2003). Sendo assim, é preciso estabelecer um equilíbrio que proporcione um desenvolvimento sustentável. Nesse sentido, acredita-se que o estudo em questão possa contribuir para que seja alcançado esse desenvolvimento, posto que, de acordo com Ab'Saber e Muller-Plantenberg (1994) a correta análise de impactos ambientais é o único instrumento pelo qual se poderá limitar as agressões ao meio ambiente, associados às reestruturações da conjuntura econômica das sociedades e dos países.

Segundo o Report of the World Commission on Environment and Development: Our Common Future (Relatório da Comissão Mundial em Meio Ambiente e Desenvolvimento: Nosso Futuro Comum), também conhecido como "Relatório Brundtland": "Desenvolvimento sustentável é o desenvolvimento que satisfaz às necessidades do presente sem comprometer a capacidade de as futuras gerações satisfazerem suas próprias necessidades" (ONU, 1987). O relatório teve como um de seus resultados a recomendação da realização de uma conferência sobre o meio ambiente e o desenvolvimento em 1989 que culminou em uma outra em 1992, que ficou conhecida como Eco-92, onde 179 governos aceitaram adotar o programa que ficou conhecido como Agenda 21 (ECOLNEWS, 2009). A Agenda 21 é um documento que estabelece a importância de cada país a se comprometer a considerar a busca de soluções para problemas sócio-ambientais, de forma local e global.

Esse relatório ressalta a interligação entre economia, tecnologia, sociedade e política e chama a atenção para uma nova postura, focada na responsabilidade socioambiental de geração a geração e entre os membros da mesma geração. Em consonância com esse relatório, apresentamos a seguir algumas das medidas que se pode relacionar à exploração de combustíveis fósseis, a serem tomadas pelos países do mundo inteiro no âmbito se suas jurisdições:

- Preservação da biodiversidade e dos ecossistemas;

- Diminuição do consumo de energia e desenvolvimento de tecnologias que• admitem o uso de fontes energéticas renováveis;

- Aumento da produção industrial nos países não-industrializados à base de tecnologias ecologicamente adaptadas;

- Controle da urbanização selvagem e integração entre campo e cidades menores.

Ainda em relação ao mesmo relatório, segue abaixo algumas metas internacionais, tendo como agentes as diversas instituições internacionais:

- As organizações do desenvolvimento devem adotar a estratégia do 
desenvolvimento sustentável;

- A comunidade internacional deve proteger os ecossistemas supranacionais como a Antártica, os oceanos, o espaço;

- A ONU deve implantar um programa de desenvolvimento sustentável.

Na tentativa de se estabelecer esse desenvolvimento sustentável, os países recorrem a procedimentos como o controle da exploração dos recursos ambientais através do licenciamento ambiental. O licenciamento ambiental é uma forma de fiscalizar o uso dos recursos naturais de maneira que ocorra a menor quantidade de danos ambientais possível. No contexto do licenciamento ambiental, existem vários tipos de licença de acordo com a fase e tipo do empreendimento ou atividade.

Para cada tipo de licença podem ser exigidos documentos diferentes, mas que sempre visam o estudo dos impactos provocados pela atividade ao meio ambiente (social, econômico e natural) de modo a decidir pela forma de sua realização ou até pela sua não realização.

Esses estudos podem ser profundos, como no caso dos Estudos de Impacto Ambiental (EIA), ou menos detalhados como no caso dos Relatórios de Controle Ambiental (RCA). A atividade de perfuração, como é o caso da atividade em questão no presente trabalho, é dispensada da obrigatoriedade de elaboração de um EIA/RIMA, sendo realizado em seu lugar um RCA. Esse documento pode ser considerado como um Estudo de Impacto Ambiental menos aprofundado e são exigidos para empreendimentos ou atividades que não tem grande capacidade de gerar impactos ambientais. A estruturação desse tipo de documento possui escopo semelhante ao de um EIA/RIMA, no entanto, não são demandados altos níveis de especificidade em suas elaborações.

Para a facilitação da elaboração dos documentos de estudo dos impactos é comum a utilização de documentos (não obrigatórios), chamados Termos de Referência, emitidos pelos órgãos ambientais estaduais. No caso da presente análise, o órgão responsável é o Instituto de Defesa do Meio Ambiente do Rio Grande do Norte (IDEMA).

O trabalho é organizado como se segue: após a descrição da metodologia utilizada, são apresentados de forma sucinta os termos e conceitos relativos ao meio ambiente e licenciamento ambiental; em seguida, se abordou o processo de licenciamento ambiental especificamente para o Brasil; após, se apontaram algumas deficiências encontradas no RCA quando comparado com o Termo de Referência e alguns aspectos da legislação; e finalmente, foram apresentadas as conclusões e propostas de melhoria desse tipo de estudo ambiental.

\section{METODOLOGIA}

Este trabalho trata de um estudo de caso, apresenta uma análise da adequação do Relatório de Controle Ambiental da Perfuração de 6 Poços de Petróleo no Campo de Porto Carão do Município de Carnaubais / RN ao Termo de Referência disponibilizado pelo IDEMA e aos referenciais teóricos e legais vigentes.

Para atingir esse objetivo procurou-se fazer um levantamento bibliográfico que desse embasamento à análise. Inicialmente, foi realizada uma pesquisa sobre documentos de 
análise de Estudos de Impactos Ambientais, para observar o que tem sido avaliado em relação a esses documentos, e a literatura relacionada, para obter uma base teórica.

Após isso, se buscou quais são as responsabilidades em relação à elaboração de Relatórios de Controle Ambiental (RCA) previstas na legislação ambiental nos âmbitos municipal, estadual e federal.

Em seguida, considerando esse referencial bibliográfico e a documentação que orienta a elaboração de RCA (para a perfuração de poços de petróleo) fornecida pelo órgão estadual, chamado de Termo de Referência, seguiu-se a análise em si, observando os pontos não atendidos, atendidos parcialmente, plenamente ou até mesmo extrapolados do Relatório de Controle Ambiental em questão em vista de avaliar a sua adequação e tecidos comentários considerados pertinentes, levando em conta a legislação e literatura consultada quando visto ser importante.

Por fim, foram elaboradas algumas sugestões para a melhoria do processo.

Em todo este trabalho, buscou-se a imparcialidade, uma linguagem acessível ao publico e, por vim, tratar do relatório específico dando ênfase ao problema geral, como se espera de um estudo de caso.

\section{AVALIAÇÃO DE IMPACTOS AMBIENTAIS}

Para que se possa compreender melhor o tema em questão é importante definir o que é exatamente um impacto ambiental, uma Avaliação de Impacto Ambiental (AIA) e dois de seus instrumentos: o Estudo de Impacto Ambiental, mais completo, e o Relatório de Controle Ambiental, mais simples:

Impacto Ambiental: é o efeito provocado por qualquer alteração causada pelas atividades humanas ao meio ambiente. Essas ações podem ser negativas ou positivas, dependendo da intervenção desenvolvida. Além disso, podem acontecer nas esferas ecológica, social e/ou econômica. (SANCHEZ, 2006). Dentre as atividades consideradas modificadoras do meio ambiente, podem-se citar algumas ligadas à área de petróleo:

- Oleodutos, gasodutos, troncos coletores e emissários de esgotos sanitários;

- Extração de combustível fóssil (petróleo, xisto, carvão);

- Complexo e unidades industriais petroquímicas.

Avaliação de Impactos Ambientais (AIA): é usado nas políticas de ambiente e gestão ambiental como um instrumento preventivo com o intuito de assegurar que um determinado projeto que possa causar impactos significativos ao meio ambiente seja analisado e que esses impactos, por sua vez, sejam analisados e levados em consideração na aprovação de realização desse projeto (SANCHEZ, 2006). Sua realização é apoiada em estudos ambientais realizados por equipes multidisciplinares. Apresentam diagnósticos, descrições, análises e avaliações sobre os impactos ambientais efetivos e potenciais do projeto analisado.

Estudo de Impacto Ambiental e Relatório de Controle Ambiental (EIA e RCA): é um dos instrumentos de AIA. No Brasil, foi instituído dentro da política nacional do meio ambiente (PNMA), através da resolução do CONAMA N. ${ }^{\circ}$ 001/86, de 23 de janeiro de 
1986. Trata-se da execução, por equipe multidisciplinar, das tarefas técnicas e científicas destinadas a analisar, sistematicamente, por meio de métodos e técnicas de previsão dos impactos ambientais. O estudo realiza-se sob orientação da autoridade ambiental responsável pelo licenciamento do projeto em questão que, por meio de instruções técnicas específicas, ou termos de referência, indica a abrangência do estudo e os fatores ambientais a serem considerados detalhadamente, com o objetivo da obtenção de uma licença ambiental de funcionamento de um empreendimento. Quando a atividade não possui grandes possibilidades de impactos ambientais, o CONAMA pode optar pela elaboração de um Relatório de Controle Ambiental (RCA), através de resolução, no lugar do EIA. Esse é o caso do licenciamento de poços de petróleo para grupos de até 40 poços a serem licenciados de uma só vez (IDEMA, 2008). A diferença em relação ao EIA é que este estudo não tem a necessidade de ser tão abrangente e completo como o EIA.

No Brasil, o primeiro dispositivo legal relacionado à Avaliação de Impactos Ambientais se deu por meio da aprovação Lei Federal 6.938 de 31/08/1981. Essa Lei criou a Política Nacional do Meio Ambiente e estabeleceu o Sistema Nacional de Meio Ambiente (SISNAMA) como órgão executor. O SISNAMA é constituído pelos órgãos e entidades da União, dos Estados, do Distrito Federal, dos Municípios e pelas Fundações instituídas pelo Poder Público (SILVA; SILVA, 2000).

Ultimamente, diferentes impactos ambientais podem ser causados nos ecossistemas devido ao desenvolvimento de diversas atividades humanas (SÁNCHEZ, 2006). Diante disso, a preocupação das nações mundiais, e também nacional, com esse fato permitiu a criação em 31 de agosto de 1981 do CONAMA por meio da Lei $n^{\circ}$ 6.938. Esse importante órgão possui a função de "assistir o Presidente da República na formulação de diretrizes da Política Nacional do Meio Ambiente" (BRASIL, 1981, art.6º I).

\section{LICENCIAMENTO AMBIENTAL}

O procedimento de Licenciamento Ambiental é uma ferramenta usada pela administração pública na busca do controle sobre atividades humanas no que diz respeito a sua interferência nas condições ambientais, na tentativa de ajustar o desenvolvimento econômico ao uso dos recursos do meio ambiente.

Pelas leis brasileiras, para a instalação de um empreendimento ou atividade potencialmente danosa ao meio ambiente deve-se obter uma licença ambiental. Os órgãos responsáveis por esse licenciamento no âmbito dos municípios e estados são os órgãos municipais e estaduais de meio ambiente (CONDEMA, no caso de Carnaubais, e IDEMA, no caso do Rio Grande do Norte, como exposto anteriormente) e o Instituto Brasileiro do Meio Ambiente e dos Recursos Naturais Renováveis (IBAMA), na esfera federal. O IBAMA atua em projetos de infra-estrutura que atinjam mais de um estado, bem como nas atividades de petróleo e gás e na plataforma continental.

No Brasil, o Licenciamento Ambiental prevê a concessão de três tipos de Licenças (que podem ser expedidas isoladamente ou sucessivamente de acordo com a atividade a ser licenciada): Licença Prévia, Licença de Instalação e Licença de Operação (SILVA; SILVA, 2000). 
Mais especificamente, para o caso de exploração e lavra de jazidas de combustíveis líquidos e gás natural, temos o texto seguinte disposto na Resolução n ${ }^{0} 23$ / 1994 do Conselho Nacional do Meio Ambiente (BRASIL, 1994):

Art. $5^{\circ}$ Os Órgãos Estaduais de Meio Ambiente e o IBAMA, quando couber, no exercício de suas atribuições de controle das atividades descritas no artigo $2^{\circ}$, expedirão as seguintes licenças:

I - LICENÇA PRÉVIA PARA PERFURAÇÃO - LPper, autorizando a atividade de perfuração e apresentando, o empreendedor, para a concessão deste ato, Relatório de Controle Ambiental - RCA, das atividades e a delimitação da área de atuação pretendida;

II - LICENÇA PRÉVIA DE PRODUÇÃO PARA PESQUISA - LPpro, autorizando a produção para pesquisa da viabilidade econômica da jazida, apresentando, o empreendedor, para a concessão deste ato, o Estudo de Viabilidade Ambiental - EVA;

III - LICENÇA DE INSTALAÇÃO - LI, autorizando, após a aprovação do EIA ou RAA e contemplando outros estudos ambientais existentes na área de interesse, a instalação das unidades e sistemas necessários à produção e ao escoamento;

IV - LICENÇA DE OPERAÇÃO - LO, autorizando, após a aprovação do Projeto de Controle Ambiental - PCA, o início da operação do empreendimento ou das unidades.

Como se pode verificar no texto acima, para o licenciamento da atividade de perfuração é exigido um Relatório de Controle Ambiental. Nessa mesma resolução, a responsabilidade de elaboração do relatório é atribuída ao empreendedor (BRASIL, 1994):

Art. $6^{\circ}$ Para expedição das licenças descritas no artigo anterior, o órgão ambiental competente se utilizará dos seguintes instrumentos:

[...]

II - RELATÓRIO DE CONTROLE AMBIENTAL - RCA, elaborado pelo empreendedor, contendo a descrição da atividade de perfuração, riscos ambientais, identificação dos impactos e medidas mitigadoras;

$[\ldots]$

No caso de um Estudo de Impacto Ambiental, sua elaboração não pode ficar a cargo do empreendedor, como podemos ver em BRASIL (1986):

Artigo $7^{0}$ - O estudo de impacto ambiental será realizado por equipe multidisciplinar habilitada, não dependente direta ou indiretamente do proponente do projeto e que será responsável tecnicamente pelos resultados apresentados.

Pode-se perceber que a imparcialidade prevista na resolução de 1986 para os EIA/RIMA não é prevista na resolução de 1994 para os RCA. Vale ressaltar também que, apesar dessa tentativa de imparcialidade por parte da resolução mais antiga, está escrito no Artigo $8^{\circ}$ da mesma que a responsabilidade de pagamento de todas as despesas ocorre por conta da empresa empreendedora. Na prática, o que acontece é que a empresa empreendedora contrata o serviço para o estudo ambiental e, tendo esse direito de escolha em relação à empresa realizadora do estudo, não se tem a imparcialidade necessária ao estudo. Podemos comprovar pelo artigo produzido pelo Ministério Público da União que os estudos acabam nunca decidindo pela não realização do empreendimento (BRASIL, 2004). 
O Relatório de Controle Ambiental (RCA) substitui o EIA/RIMA para empreendimentos que se considera não ter grande capacidade de gerar impactos ambientais. Tem estrutura semelhante a do EIA/RIMA, mas é exigido um nível menor de detalhamento, além do que já foi considerado no parágrafo anterior. O caso da perfuração de poços de petróleo é um dos considerados de pouco potencial impacto ambiental.

No quadro 1, apresentam-se os tipos de licença e as atividades autorizadas pelas mesmas, como consta no sítio da Agência Nacional do Petróleo, Gás Natural e Bio-combustíveis:

\section{ANÁLISE DO “RELATÓRIO DE CONTROLE AMBIENTAL DA PERFURAÇÃO DE 6 POÇOS DE PETRÓLEO DO CAMPO DE PORTO CARÃO NO MUNICÍPIO DE CARNAUBAIS / RN - REVISÃO 00”}

Este estudo foi desenvolvido em duas etapas:

A primeira foi realizada por meio da leitura detalhada do RCA do Campo de Porto Carão e na segunda foi feita a comparação com o Termo de Referência e a legislação ambiental federal vigente, com interpretações da mesma presente na literatura.

Considerando que um RCA se trata de um EIA simplificado, além do "Termo de Referência - Elaboração de Relatório de Controle Ambiental (RCA) referente ao Licenciamento Prévio para Perfuração de Poços de Petróleo” (IDEMA, 2008), se utilizou a lista de verificação proposta em Sanchez (2006) (com as modificações sugeridas por este se tratar de um EIA para a construção de uma rodovia) como guia principal e a resolução CONAMA nº 001 / 1986 (BRASIL, 1986) como referências para esta análise.

\subsection{CONSIDERAÇÕES GERAIS SOBRE O RCA EM ANÁLISE}

No RCA em questão, quando analisado em relação ao TR disponibilizado pelo IDEMA e em relação à lista de verificação proposta por Sanches (2006), foram encontradas algumas inconsistências. Neste tópico listaremos os pontos considerados mais relevantes.

De uma forma geral, alguns erros de português pontuais e conteúdos localizados nos itens inadequados do relatório apontam para uma falha de revisão. Os erros teriam passado sem correção por cada membro da equipe, que, presume-se, teriam lido todo o documento. Em alguns pontos, até dificulta a compreensão, como no caso abaixo:

O projeto de perfuração, dos poços PC 775-9421-751a, PC 777-9421-751, PC 777-9421-751a, PC 777-9421-751b, PC 777-9421-751c e PC 787-9421-751, constituem uma das fases da exploração de petróleo, e tem como objetivo, neste caso específico, em se tratando de campos conhecidamente produtores, objetiva-se a produção (destaque nosso).

Ainda em relação ao parágrafo apresentado, o escrito refere-se a um objetivo do projeto, mas se encontra como objetivo sócio-econômico.

Apresenta-se aqui uma análise mais detalhada seguindo o roteiro de Sanchez (2006), item a item, por se tratar de um documento mais completo, o que possibilita uma melhor avaliação. Para melhor comparação com os itens do Termo de Referência, foi colocado entre parênteses ao lado de cada item o item que mais se aproximou do abordado na lista de verificação. 


\begin{tabular}{|c|c|c|c|}
\hline ATIVIDADE & TIPO DE LICENÇA & $\begin{array}{c}\text { ESTUDO } \\
\text { AMBIENTAL } \\
\text { APLICÁVEL }\end{array}$ & FINALIDADE \\
\hline $\begin{array}{l}\text { PERFURAÇÃO } \\
\text { (Programa Exploratório } \\
\text { Mínimo contratado com } \\
\text { a ANP) }\end{array}$ & $\begin{array}{l}\text { Licença Prévia para } \\
\text { Perfuração - (LPper) }\end{array}$ & $\begin{array}{l}\text { Relatório de Controle } \\
\text { Ambiental - RCA }\end{array}$ & $\begin{array}{l}\text { Autoriza a atividade de } \\
\text { perfuração. }\end{array}$ \\
\hline $\begin{array}{l}\text { PRODUÇÃO PARA } \\
\text { PESQUISA } \\
\text { (Teste de Longa } \\
\text { Duração-TLD, } \\
\text { autorizado pela ANP) }\end{array}$ & $\begin{array}{l}\text { Licença Prévia de } \\
\begin{array}{l}\text { Produção para } \\
\text { Pesquisa - (LPpro) }\end{array}\end{array}$ & $\begin{array}{l}\text { Estudo de Viabilidade } \\
\text { Ambiental - EVA }\end{array}$ & $\begin{array}{l}\text { Autoriza a realização do } \\
\text { Teste de Longa Duração } \\
\text { - TLD, }\end{array}$ \\
\hline $\begin{array}{l}\text { SISTEMAS DE } \\
\text { PRODUÇÃO E } \\
\text { ESCOAMENTO } \\
\text { (Sistema de Produção e } \\
\text { Escoamento em novo } \\
\text { campo ou bloco - Plano } \\
\text { de Desenvolvimento } \\
\text { aprovado pela ANP) }\end{array}$ & $\begin{array}{l}\text { Licença de Instalação - } \\
\text { (LI) }\end{array}$ & $\begin{array}{l}\text { Estudo de Impacto } \\
\text { Ambiental e respectivo } \\
\text { Relatório de Impacto } \\
\text { Ambiental - EIA/RIMA. }\end{array}$ & $\begin{array}{l}\text { Autoriza, após a } \\
\text { aprovação do EIA/RIMA } \\
\text { com a respectiva } \\
\text { realização de Audiência } \\
\text { Pública, a instalação de } \\
\text { sistemas e unidades } \\
\text { necessárias à produção e } \\
\text { ao escoamento. }\end{array}$ \\
\hline $\begin{array}{l}\text { SISTEMAS DE } \\
\text { PRODUÇÃO E } \\
\text { ESCOAMENTO } \\
\text { (Áreas onde já se } \\
\text { encontra implantada a } \\
\text { atividade) }\end{array}$ & $\begin{array}{l}\text { Licença de Instalação } \\
\text { (LI) }\end{array}$ & $\begin{array}{l}\text { Relatório de Avaliação } \\
\text { Ambiental - RAA }\end{array}$ & $\begin{array}{l}\text { Autoriza, após } \\
\text { aprovação do RAA, a } \\
\text { instalação de sistemas e } \\
\text { unidades adicionais } \\
\text { necessários à produção e } \\
\text { ao escoamento. }\end{array}$ \\
\hline $\begin{array}{l}\text { SISTEMAS DE } \\
\text { PRODUÇÃO E } \\
\text { ESCOAMENTO }\end{array}$ & $\begin{array}{l}\text { Licença de Operação } \\
\text { (LO) }\end{array}$ & $\begin{array}{l}\text { - Projeto de Controle } \\
\text { Ambiental (PCA). }\end{array}$ & $\begin{array}{l}\text { Autoriza, após o } \\
\text { atendimento das } \\
\text { condicionantes da LI, a } \\
\text { aprovação do PCA, do } \\
\text { PEI e da realização da } \\
\text { vistoria técnica, o início } \\
\text { da operação do } \\
\text { empreendimento. }\end{array}$ \\
\hline $\begin{array}{l}\text { AQUISIÇÃO DE } \\
\text { DADOS SÍSMICOS } \\
\text { (Autorização da ANP } \\
\text { para realização da } \\
\text { atividade de } \\
\text { Levantamento de Dados } \\
\text { Sísmicos Marítimos, não } \\
\text { exclusivos) }\end{array}$ & $\begin{array}{l}\text { Licença de Operação - } \\
\text { (LO) }\end{array}$ & Estudo Ambiental (EA) & $\begin{array}{l}\text { Autoriza, apos aprovação } \\
\text { do EA, o inicio da } \\
\text { atividade de } \\
\text { levantamento de dados } \\
\text { sísmicos marítimos. }\end{array}$ \\
\hline $\begin{array}{l}\text { AQUISIÇÃO DE } \\
\text { DADOS SÍSMICOS } \\
\text { (Contrato de Concessão } \\
\text { ANP do Bloco, que } \\
\text { prevê atividades de } \\
\text { pesquisa, } \\
\text { compreendendo a } \\
\text { Aquisição de Dados } \\
\text { Sísmicos Marítimos, } \\
\text { exclusivos) }\end{array}$ & $\begin{array}{l}\text { Licença de Operação } \\
\text { (LO) }\end{array}$ & Estudo Ambiental (EA) & $\begin{array}{l}\text { Autoriza, apos aprovação } \\
\text { do EA, o inicio da } \\
\text { atividade de } \\
\text { levantamento de dados } \\
\text { sísmicos marítimos. }\end{array}$ \\
\hline
\end{tabular}




\subsection{SUMÁRIO (NÃO ABORDADO NO TERMO DE REFERÊNCIA)}

Existe sumário paginado que permite encontrar rapidamente os assuntos constituintes do relatório. O termo de referência não cita quais seriam as exigências no uso de sumário mas acreditamos que seria parte essencial.

\subsubsection{Introdução (não abordado no Termo de Referência)}

Não há introdução, mas o termo de referência não prevê introdução. Esse tópico, sugerido por Sanchez (2006) poderia ser relevante para uma melhor contextualização do estudo.

\subsubsection{Informações Gerais}

\subsubsection{Identificação do Empreendedor (item 1.1 do Termo de Referência)}

O empreendedor foi identificado corretamente. O termo de referência foi atendido na sua totalidade neste item (endereço, CNPJ, telefones...).

\subsubsection{Identificação da empresa responsável pelo Relatório de Controle Ambiental (item 2 do Termo de Referência)}

Neste caso, a Resolução CONAMA nº 23 / 1994 (CONAMA, 1994) prevê a realização deste relatório pela própria empresa do empreendimento, o que não exclui a possibilidade de também ser elaborado por uma empresa contratada para esse fim.

Os itens do termo de referência foram completamente atendidos. A empresa foi identificada de forma adequada, constando dados essenciais (como endereço e CNPJ) como ocorreu na identificação da empresa do empreendimento.

\subsubsection{Histórico do Empreendimento (não abordado no termo de referência)}

Não foi acrescentado o histórico anterior da região, mas o fato de já existir exploração anterior foi usado como um ponto a favor na obtenção do licenciamento pretendido com o atual relatório.

Existe descrição detalhada dos estudos que levaram ao projeto atual (incluindo a metodologia utilizada).

\subsubsection{Objetivos do Empreendimento e sua justificativa (item 3.1 do Termo de Referência)}

Apesar de previsto pelo termo de referência, neste tópico do RCA não são citados claramente os objetivos, limita-se a apresentar as vantagens da realização do empreendimento, o que pode ser interpretado como justificativa.

Alega que os royalties do petróleo são "uma das principais fontes de renda do estado" e que "a atividade petrolífera assume vital importância para a economia do Rio Grande do 
Norte", mas tenta justificar isso apresentando apenas um quadro com os valores desses royalties, sem mostrar quadro comparativo com outras fontes que endosse tal afirmação. Sendo esse o ponto principal do item 3.1, a justificativa poderia ser considerada insuficiente. Vale ressaltar que não foi tratado como medida compensatória, e sim como objetivo sócio-econômico.

O fato de o estado do Rio Grande do Norte ser o terceiro maior produtor não demonstra a importância do petróleo para o estado e sim a importância do petróleo extraído no estado para o país. Apenas os royalties poderiam não compensar os passivos ambientais para o estado, então esse argumento em especial deveria se valer da importância dessa exploração para o país. Vale ressaltar que o petróleo é de propriedade da União e não do estado. Deveria ter sido dado enfoque ao estado, abordando os ganhos e perdas que fossem realmente pertinentes.

Além disso, a equipe usou o fato de que já havia exploração antes como argumento a favor da obtenção da licença para a atividade atual, mas não foram feitas considerações sobre os pontos negativos da soma de mais exploração ao local, se limitou a alegar que não afetaria a produção rural caso se cumpram as medidas mitigadoras propostas. Ou seja, o que parece um argumento a favor poderia na verdade ser um argumento contra. Poder-se-ia considerar que a exploração da região já estaria provocando um impacto total muito grande (somando a contribuição de cada um dos poços já existentes) e que não suportaria a instalação de mais poços ou, o mais provável, que ainda haveria espaço para mais exploração. Teria sido melhor informar que apesar de já haver exploração, ainda haveria espaço para a instalação de mais poços e justificar tal informação.

Foi considerado também o aumento da produção interna provocando diminuição da importação, o que demonstra mais uma vez o benefício para o país e não para o estado.

Apesar de estar no Termo de Referência que se justifique a escolha do local de implantação, isso não consta no subitem previsto no RCA em questão, apenas consta o fato de a região não se tratar de uma área protegida.

\subsubsection{Localização do Empreendimento (item 1.2 do Termo de Referência)}

Foram dadas as coordenadas UTM (Universal Transverse Mercator - um método que usa uma grade para mapear localizações na superfície da terra) e existem mapas montados em software adequado com as localizações dadas de forma suficientemente detalhada.

\subsubsection{Etapas de Implantação do Empreendimento}

Descreveram-se com detalhes as etapas de perfuração. O detalhamento do processo e dos equipamentos utilizados é previsto no termo de referência e foi bem apresentado no RCA.

Não é colocado nenhum cronograma da operação de perfuração.

Houve extensa descrição das linhas de surgência, incluindo a instalação, o que não estava explícito no termo de referência, mas as medidas mitigadoras, que não previstas nesse item, foram apenas citadas. Não foram colocados nenhum dos mapas requeridos pelo termo. 


\subsubsection{Planos e Programas Governamentais Co-localizados}

Segundo o RCA, não existe nenhum plano ou programa governamental na área do empreendimento, essa informação não pôde ser confirmada, o que pode apontar realmente para a não-existência.

\subsubsection{Fontes de Recursos Financeiros (não abordado no Termo de Referência)}

Não abordado no RCA por não estar previsto no Termo de Referência, mas fica claro que os Recursos devem partir da empresa empreendedora.

\subsubsection{Compatibilidade do Empreendimento com a Legislação Ambiental (não previsto no Termo de Referência)}

Não foi dado o enquadramento legal da atividade. Talvez por se tratar de um RCA e por esse item não estar previsto no Termo de Referência. Não resta dúvida de que essa é uma informação essencial a este tipo de atividade, a questão é onde deve ser obrigatório utilizála. Se estiver sendo feito um EIA da região, esse enquadramento legal poderia constar nesse documento, que poderia cobrir o RCA e assim evitar redundância.

\subsubsection{Atividades de Consulta Pública Realizadas (não previsto no Termo de Referência)}

As atividades de consulta pública foram realizadas para fins de diagnóstico ambiental. Apesar de não constar no termo de referência, é etapa prevista em legislação.

\subsubsection{Caracterização do Empreendimento (item 3.2 do Termo de Referência)}

\subsubsection{Projeto Funcional (itens 3.2.1 a 3.2.7 do Termo de Referência)}

A descrição da perfuração e instalação dos poços foi realizada de maneira detalhada, como exigido pelo Termo de Referência. Já a relação dos equipamentos foi realizada de forma genérica chegando a constar que a perfuração será realizada por "sonda terrestre a ser determinada de acordo com a disponibilidade no momento da perfuração”. O Termo de Referência pede o "nome comercial”, então esse deve ser o nível de profundidade que deve ser atendido pelo Relatório.

A descrição dos fluidos foi realizada de maneira adequada.

No subitem previsto para a caracterização dos resíduos o texto de cabeçalho do item ficou exatamente igual ao do Termo de Referência, provocando falta de sentido: "3.2.3 Especificação entre outros aspectos da geração de resíduos, tais como:’.

No caso das emissões gasosas, não foi especificado que tipo de combustível será queimado nem o produto dessa queima. Também foram desconsideradas as emissões gasosas dos veículos que transitarão no local. 
Para óleos lubrificantes, resíduos não-combustíveis, esgotos sanitários e outros resíduos industriais, tanto a descrição como o procedimento parecem adequados.

É apresentada uma tabela bastante completa (tabela 3.2.2 no RCA) com a descrição dos resíduos que serão produzidos mas esta não está ligada ao processo operacional do poço como prevê o Termo de Referência. Ou seja, o processo operacional apenas da fase de perfuração está descrito em um item e os resíduos em outro. Não consta a descrição das outras etapas, nem de que etapa é cada um dos resíduos apresentados na tabela.

Na parte de descrição das linhas de surgência prevista pelo Termo de Referência não foram colocadas as figuras requeridas, que deveriam apresentar o seu traçado. Foram acrescentadas apenas as figuras genéricas com esquemas de instalação necessárias ao entendimento do procedimento de instalação, que foi explicado em detalhes. As linhas de surgência foram acrescentadas no mapa de influência (mas isso não foi citado no item).

\subsubsection{Alternativas Tecnológicas}

Não foram citadas alternativas tecnológicas ou locacionais, foi apresentada apenas uma alternativa. Outra alternativa que poderia ser citada e ter justificada sua não-utilização, o que provavelmente seria o caso, seria a utilização de perfuração direcional, aproveitando poços próximos.

\subsubsection{Alternativas de localização}

Não foram dadas alternativas de localização.

\subsubsection{Descrição da instalação do poço}

Já realizada no item “3.1”.

\subsubsection{Descrição dos Principais Serviços na Etapa de Construção}

Descreveu-se com detalhes a perfuração (atividade causadora do impacto ambiental negativo) e apenas citou-se que as normas da ANP seriam seguidas no caso de arrasamento do poço (medida mitigadora de impacto).

Não foi abordada a quantidade de trabalhadores no processo, nem os critérios de contratação e dispensa. Também não foi descrita qual a necessidade de insumos e matérias primas.

Não foi apresentado o cronograma.

Não foram descritas atividades que utilizem água ou outro recurso natural.

\subsubsection{Descrição dos principais serviços na etapa de operação do poço}

Não foi realizada essa descrição. 


\subsubsection{Diagnóstico Ambiental (item 5 do Termo de Referência)}

Falou-se sobre diagnóstico ambiental no item de Delimitação da área de influência.

Foi incluído um subitem com o processo metodológico adotado pela empresa para a elaboração do RCA, apesar de o termo de referência não prever esse item. Além disso, o item está no capítulo de objetivos e justificativas, o que não é o item previsto no Termo de Referência.

\subsubsection{Delimitação da Área de Estudo (item 4 do Termo de Referência)}

Não é descrito o que foi considerado para a delimitação das áreas de influência direta e indireta. Não é apresentada nenhuma justificativa para os 300 metros escolhidos como área de influência indireta (AII).

As áreas de influência são apresentadas em um dos mapas do relatório. A AII, segundo a Resolução CONAMA 01/86, deve conter no mínimo a bacia hidrográfica onde se localiza a intervenção. A AII considerada no RCA é cortada pelo Rio Piranhas (como pode ser visto nos mapas disponibilizados no relatório), então a AII deveria abranger o rio.

O Termo de Referência prevê a descrição dos meios físicos biológicos e antrópicos por meio de mapas, mas neste item do RCA só há referência a um mapa, o das áreas de influência direta e indireta.

Parte das análises das áreas de influência pode ter sido aproveitada de outros relatórios, o que é compreensível e levanta a questão da necessidade dessa repetição. Talvez devesse existir uma AIA maior elaborado para a região e com certa vigência e, sendo assim, os RCA poderiam ficar mais enxutos desde que estivessem dentro da abrangência e prazo de validade do EIA.

\subsubsection{Meio Físico (item 5.1 do Termo de Referência)}

No capítulo 5 do RCA está escrito “dezenove poços” se referindo ao empreendimento em questão que possui apenas 6 (seis) poços. Isso pode ser um indício que partes do texto foram reaproveitadas de outros relatórios sem a devida análise de adequação ao empreendimento atual. Vale ressaltar que esse erro passou na revisão da equipe que elaborou o RCA e no órgão fiscalizador.

A caracterização do meio físico foi realizada de maneira eficiente e adequada ao que foi requerido no Termo de Referência, incluindo mapas geológicos, estratigráficos, fotografias do solo, uso de poços d'água, etc. Vale ressaltar que a cidade não foi considerada no mapa da área de influência indireta.

\subsubsection{Meio Biótico (item 5.2 do Termo de Referência)}

Foram apresentados dados de fontes primárias (equipe e moradores do local) e de fontes secundárias. Mais uma vez, tudo bem fundamentado e bem apresentado através de fotografias do local e tabelas com os levantamentos da fauna e flora. 
Não foi acrescentado o mapa 1:25000 como previsto no Termo de Referência.

\subsubsection{Meio Antrópico (item 5.3 do Termo de Referência)}

A abrangência econômica é indicada apenas como a abrangência direta, o pagamento do uso do terreno (Direito de Superfície) e o pagamento dos royalties.

Segundo a definição do dicionário, sócio-econômico seria "Relativo aos problemas sociais na sua relação com os problemas econômicos”. Sendo assim, temos itens julgados como sócio-econômicos que na verdade se encaixariam como objetivos e justificativas gerais.

O mapa utilizado para uso e ocupação do solo foi de 1:10000 no lugar do de 1:25000 previsto.

Foram levantados apenas dados secundários, alegando-se a inexistência de distritos, comunidades ou sítios em um raio de um quilômetro das locações.

Não foram consideradas as caracterizações sócio-econômicas para a área de influência do empreendimento por estarem a mais de $1000 \mathrm{~m}$ do empreendimento e ter-se considerado até 300 m como área de influência indireta.

\subsubsection{Qualidade Ambiental}

O texto caracteriza bem a situação antes da perfuração.

\subsubsection{Análise dos Impactos (item 6 do Termo de Referência)}

\subsubsection{Identificação dos Impactos Ambientais}

O procedimento usado na identificação dos impactos é descrito no RCA.

A descrição dos impactos ambientais (diretos e indiretos) foi realizada de forma sistemática, através de tabelas bem organizadas e de fácil compreensão, mas os impactos não foram avaliados com e sem as medidas mitigadoras como requerido pelo Termo de Referência.

Mais uma vez a possibilidade de incêndio e explosão não foi levada em consideração.

\subsubsection{Previsão e Avaliação dos Impactos Ambientais}

Nenhuma estimativa quantitativa dos impactos foi apresentada. A abordagem foi somente qualitativa para todos os itens.

Não foram utilizados nenhum modelo matemático.

Aparentemente, foram necessárias poucas modificações para as características locais. 
Foram usados critérios de importância dos impactos.

Não foi realizado o balanço entre os impactos positivos e negativos, nem foi avaliada a viabilidade do empreendimento neste item.

Não foram levados em consideração os impactos e as estratégias de mitigação dos estudos para os outros poços já existentes.

\subsubsection{Análise Preliminar de Riscos}

Foram detalhadas três situações que impõem riscos ambientais: “Teste de Formação", "Derramamento de Óleo" e "Risco de fluxo indesejável, incêndio e explosão". Essas situações foram descritas de forma bastante resumida quando comparadas às descrições dos procedimentos de perfuração. Considerando-se que o relatório tem como foco esses impactos ambientais, poder-se-ia ter-se dado maior detalhamento a esses problemas.

Apesar de ter sido descrito que há risco de explosão, não foram considerados os procedimentos de socorro a feridos nos procedimentos a serem adotados em caso de emergência. Limitou-se a abordagem relativa ao derramamento de óleo.

\subsubsection{Prognóstico da Qualidade Ambiental Futura com e sem o Empreendimento}

Não foi realizado este prognóstico.

\subsubsection{Programas de Gestão Ambiental}

\subsubsection{Programas de Gestão (item 7 do Termo de Referência)}

Os procedimentos para as medidas mitigadoras deste item ficaram isolados dos impactos ambientais apresentados em item anterior, foram colocadas como medidas complementares e, quase sempre, não foram associados os relativos impactos. Também não há descrição de como as medidas mitigadoras serão colocadas em prática, essas são somente citadas nos dois itens.

Os itens de caracterização previstos no Termo de Referência para este item foram relatados da maneira adequada mas no item de identificação dos impactos.

Não é descrito o procedimento para a escolha dos processos de mitigação. Também não se é levado em consideração os custos previstos para essas mitigações. Esse pode ser um caso onde caberia alguma ferramenta de apoio à decisão que poderia ser usada na "calibração" ou até mesmo escolha do procedimento a ser executado. De forma geral, percebe-se uma total ausência de análise financeira. Não se considera uma análise quantitativa das vantagens do empreendimento versus o passivo ambiental, a chamada "ecoeficiência" em Almeida (2002).

Não foram definidos claramente os procedimentos para abandono do local caso o poço não seja viável, o que acarretaria abandono imediato e, sendo assim necessária a descrição do 
procedimento já no relatório em questão. Apenas foi citado que se usaria normas da ANP, sem definir que normas seriam essas ou citar seu conteúdo.

\subsubsection{Plano de Monitoramento Ambiental (item 8 do Termo de Referência)}

É citado um Programa de Monitoramento Ambiental Regional das Atividades Terrestres da PETROBRAS no estado do Rio Grande do Norte e um Plano de Acompanhamento das Medidas Mitigadoras, ambos, segundo o RCA, iniciados em 2005.

Os requisitos do Termo de Referência, de uma maneira geral, não são atendidos para esse item.

\subsubsection{Sistema de Gerenciamento Ambiental}

Mesmo problema do item anterior (os dois itens são interdependentes).

\subsubsection{Síntese e Conclusões (item 9 do Termo de Referência)}

As principais conclusões do estudo foram retomadas neste item. O que é previsível, já que não houve restrições de espécie alguma, nem alternativas tecnológicas ou locacionais e nem a análise da possibilidade de não realização do empreendimento.

\subsubsection{Referências Bibliográficas (item 11 do Termo de Referência)}

É apresentada uma lista de referências no final do documento mas a quantidade de referências realmente citadas no texto é consideravelmente menor. De acordo com a norma da ABNT 10719 para apresentação de relatórios técnico-científicos de 1989: "Não devem ser referenciadas fontes bibliográficas que não foram citadas no texto” (NBR 10719) (no Termo de Referência consta que a norma técnica específica deve ser atendida). Na mesma norma ainda tem-se que se for desejado adicionar referências que foram utilizadas, mas não citadas, estas devem ser colocadas em outro item intitulado "Bibliografia Recomendada” (item opcional). Isso demonstra uma preocupação da ABNT em deixar claro o que foi efetivamente usado como referência no texto.

Existem estudos não publicados nas referências onde não está clara a sua localização para consulta pública. Este é um ponto bastante crítico, os RCA são documentos de muito difícil acesso por parte da sociedade no Rio Grande do Norte.

\subsubsection{Glossário de Termos Técnicos Utilizados (não abordado no Termo de Referência)}

Não foi elaborado um glossário e o Termo de Referência também não exigia a elaboração de um.

\subsubsection{Equipe Técnica (item 10 do Termo de Referência)}

Os participantes do estudo são identificados com seus respectivos números de registro profissional (nos casos aplicáveis) e é mencionada com detalhes gerais a participação no 
estudo. Obedecendo estes termos também está em conformidade com o Termo de Referência.

\subsubsection{Anexos}

Nenhum anexo do texto deixou de ser apresentado. A documentação fotográfica prevista como anexo não foi acrescentada, mas consta do próprio RCA.

\subsubsection{Relatório de Impacto Ambiental}

Não é previsto para o caso de elaboração de RCA, dado a sua profundidade reduzida.

\section{CONCLUSÕES E PROPOSTAS}

Após a análise realizada sobre o RCA em questão, conclui-se basicamente que o órgão licenciador (caso tenha recebido essa "Revisão 00") deveria ter devolvido o documento à equipe elaboradora para revisão, apontando as pequenas falhas e pontos passíveis de correção ou aprimoramento.

Caso esta tenha sido a versão aprovada pelo IDEMA, as falhas pontuais de português e revisão podem indicar a mecanização do processo. Os Relatórios de Controle Ambiental podem estar sendo apresentados apenas como documento burocrático. Como ocorre nos EIA/RIMA, como se pode ver em artigo do Ministério Público da União (MPU, 2004), é provável que em nenhum RCA se tenha concluído pela inviabilidade ambiental do empreendimento (considerando que o RCA se trata de um documento ao qual recaem menos exigências).

Pode ser útil uma maior padronização dos procedimentos e maior compartilhamento e informação através de Bancos de Dados públicos obtidos por pesquisas (EIA) que poderiam ser efetuadas de forma periódica e permanente pelo próprio governo, evitando a necessidade de retrabalho por parte dos requerentes do licenciamento, que se focariam simplesmente nos aspectos intimamente relacionados ao empreendimento em análise.

Face à realidade contatada no estudo em análise, sugere-se que sejam criados procedimentos usando ferramentas de apoio à decisão (como análise multicritério) na escolha dos procedimentos de mitigação dos impactos ambientais e alternativas tecnológicas. Essas ferramentas poderiam ser auxiliadas por bancos de dados de procedimentos anteriores, estatísticas desses dados, procedimentos para previsão de impactos usando tratamento estatístico adequado, podendo até valer-se de ferramental matemático e estatístico para determinados parâmetros, definidos pelo órgão. Isso poderia ajudar a reduzir a subjetividade e incerteza do processo.

Considerando que o documento tenha sido elaborado de forma adequada, ou seja, que nada (ou pouco) precise ser esclarecido pessoalmente ou através de apresentação, poderia existir no processo um prazo de apreciação por parte da sociedade, no qual o documento ficaria a disposição na internet a quem interessasse. A consulta aos envolvidos (stakeholders) ${ }^{1}$ é etapa crucial do processo de tomada de decisão em um regime democrático (MUNDA,

$1 \quad$ São pessoas e grupos capazes de influenciar ou ser influenciados pelos resultados estratégicos alcançados e que possuem reivindicações a respeito do desempenho da organização. 
2008) e essa participação somada com a consideração de um critério que preveja a justiça social na avaliação é muito importante para que ocorra o verdadeiro desenvolvimento sustentável, como foi feito no modelo proposto em Omann et. al (2008). Não é possível se tomar uma decisão justa utilizando simplesmente parâmetros técnicos, por melhor que tenham sido desenvolvidos e aplicados, é uma impossibilidade inerente à própria natureza da tomada de decisões onde existem tantos interesses envolvidos. Essa disponibilização para apreciação pública durante o processo da tomada de decisão (para todos EIA/RIMA e relatórios ambientais) através da internet proporcionaria uma melhor intervenção de entidades ambientais governamentais ou não, que poderiam contribuir grandemente com a fiscalização e melhoramento contínuo do processo. Certamente haveria, no mínimo, sugestões de melhoramento tanto à empresa realizadora do estudo quanto ao órgão fiscalizador.

\section{REFERÊNCIAS}

1. ALMEIDA, Fernando; O Bom negócio da sustentabilidade. Ed. Nova Fronteira. Rio de Janeiro, 2002.

2. AB'SABER, A. N.; MÜLLER-PLANTENBERG, C. Apresentação. In: MÜLLERPLANTENBERG, C.; AB'SABER, A. N. (Orgs.). Previsão de impactos: o estudo de impacto ambiental no leste, oeste e sul. Experiências no Brasil, na Rússia e na Alemanha. São Paulo: Editora da Universidade de São Paulo, 1994.

3. ANP - Agência Nacional do Petróleo, Gás Natural e Biocombustíveis. Disponível em: www.anp.gov.br, acesso em 04/06/2009.

4. CAVALCANTI, Clóvis et al. Desenvolvimento e natureza: estudos para uma sociedade sustentável. $4^{\mathrm{a} e d . ~ S a ̃ o ~ P a u l o: ~ C o r t e z, ~} 2003$.

5. BRASIL. Lei $n^{0}$ 6.938, de 31 de agosto de 1981. Dispõe sobre a Política Nacional do Meio Ambiente, seus fins e mecanismos de formulação e aplicação, e dá outras providencias. Diário Oficial [da] República Federativa do Brasil, Brasília, DF, 02 set.1981

6. BRASIL. Conselho Nacional do Meio Ambiente. Resolução $\mathbf{n}^{\mathbf{0}} \mathbf{0 0 1}$, de 23 de janeiro de 1986. Dispõe sobre critérios básicos e diretrizes gerais para o Relatório de Impacto Ambiental RIMA. Diário Oficial [da] República Federativa do Brasil, Brasília, DF, 17 fev. 1986..

7. BRASIL. Ministério Público da União. Deficiências em estudos de Impacto ambiental - Síntese de uma Experiência. Escola Superior do Ministério Público da União. Brasília, 2004.

8. BRASIL. Resolução CONAMA $\mathbf{n}^{0} 23$ / 1994. Disponível em: http://www.anp.gov.br/brasil-rounds/round1/Docs/LDOC12_pt.pdf. Acesso em: 04/06/2009.

9. ECOLNEWS. Agenda 21 - texto completo. Disponível em: http://www.ecolnews.com.br/agenda21/. Acesso em: 05/07/2009.

10. IDEMA - Instituto de Desenvolvimento Sustentável e Meio Ambiente do Rio Grande do Norte. Termo de Referência - Elaboração de Relatório de Controle Ambiental (RCA) referente ao Licenciamento Prévio para Perfuração de 
Poços de Petróleo. Natal, 2008. Disponível em: < http://www.idema.rn.gov.br >, acesso em 04/06/2009.

11. MUNDA, Giuseppe. Social Multi-Criteria Evaluation for a Sustainable Economy. Ed. Springer. Estados Unidos, 2008.

12. NBR 10719: 1989 - Apresentação de relatórios técnico-científicos Procedimento

13. OMANN, Ines; KOWALSKI, Katharina; Bohunovsky; Lisa; MADLENER, Reinhard \& STAGL, Sigrid. The Influence of Social Preferences on MultiCriteria Evaluation of Energy Scenarios. RWTH Aachen University, Institute for Future Energy Consumer, 2008.

14. ONU - Organização das Nações Unidas. Report of the World Commission on Environment and Development: Our Common Future. UN Documents Cooperation Circles, 1987. Disponível em: http://www.un-documents.net/ocf02.htm\#I, acesso em 04/06/2009.

15. SANCHEZ, Luis Enrique; Avaliação de impacto ambiental: conceitos e métodos. Ed. Oficina de Textos. São Paulo, 2006.

16. SILVA, Elias \& SILVA, Luís César. Impacto Ambiental. Alegre - ES, 2000. Disponível em: http://www.agais.com/impacto.htm. Acesso em 04/06/2009. 